\title{
Looking after consumers in the new NHS
}

\author{
Community health councils will need to be strong and skilled
}

From the start the National Health Service has been subject to a tension between accountability to the centre and responsiveness to the local community. On the one hand the Secretary of State for Health is accountable to parliament for every penny spent by the NHS. On the other hand-starting with Aneurin Bevan-ministers have emphasised the need to ensure that health authorities are sensitive to the needs of their localities and of those who use their services. The first objective suggests that health authorities must be part of a managerial hierarchy; the second suggests that they should represent the communities they serve.

Successive reorganisations of the NHS have tried different ways to reconcile these conflicting objectives. The 1974 model saw health authorities as essentially managerial bodies and invented community health councils to provide for "the expression of local public opinion." The 1982 model moved in the opposite direction, putting more emphasis on the representative role of the newly created district health authorities in interpreting local needs and circumstances. ${ }^{2}$ Now the 1989 model has reverted to emphasising the managerial role of health authorities, albeit with a more ruthless logic, leaving it to community health councils to represent "the interests of the local community" and to "act as a channel for consumer views."

If the 1982 reorganisation seemed to make community health councils redundant - Why have them if health authorities represent the community? - the 1989 proposals look like thrusting them into greater prominence. For if the new health authorities are clearly to be part of a managerial hierarchyaccountable to the centre-then responsibility for representing the interests of the community falls exclusively on the councils. That should mean an increase in their importance, and, indeed, behind the scenes consultations are going on about what the new environment might mean for them, with the councils pressing for additional rights and NHS managers arguing for maintaining the status quo. ${ }^{+}$

Before considering whether there is a case for enlarging the influence of community health councils we need to analyse the new environment. Like its 1970s predecessor (with which it has some striking similarities in this and other respects), the 1989 white paper Working for Patients starts by diagnosing a "confusion of roles." 3 The present day regional and district authorities, with 16 to 19 members appointed directly by or on the advice of local authorities and professional bodies, are "neither truly representative nor management bodies." So their representative function is to be axed. The new health authorities will have five non-executive members and up to the same number of executive members - that is, managers. The model is clearly that of a company board-although ministers have been anxious to emphasise that it is not necessarily the intention to appoint businessmen but rather to appoint people with a variety of personal qualities and professional skills. ${ }^{5}$ However this may be interpreted in practice, there will be no one on the new authorities with a responsibility for arguing the case for particular client groups or particular geographical localities in debates about priorities in the distribution of services.

In many respects this may turn out to be an improvement on the present system. Certainly health authorities have not been uniformly successful or effective ${ }^{6}$; nor is it self evident that priorities in resource allocation are best decided by log rolling or pushing constituency interests, whether political, geographical, or professional. In any case the new health authorities will function very differently for reasons that have nothing to do with their membership. The separation of the purchaser and provider functions should mean that the new authorities will be free to concentrate on strategic issues: on defining as purchasers the needs of their populations and on devising the best means of satisfying them, while it is left to the providers to take the day to day decisions. In this, as in other ways, the irony is that while the rhetoric of the government proposals is that of the market the reality is an emphasis on management. ${ }^{7}$ It will be the managers who will determine what consumers need and decide whether they are satisfied with what they get as well as controlling the quality of the products. There is, however, no market to control the managers. If the manager of a supermarket chain fails to be sensitive to consumer needs the market will punish him or her. If a health authority fails to be sensitive to consumer needs there is no such mechanism. If consumers switch their custom and exit into the private sector this is a bonus rather than a penalty for the NHS. There is only accountability to the centre.

Let us now return to the task of the community health councils. Given that the NHS is not a consumer market and that exit into the private sector carries no sanctions for inadequate managers, there is a case for strengthening their voice - that is, their ability to apply public pressure. But if the future role of the councils is going to be more important than in the past it is also likely to be different, for in many respects the new health authorities should be tackling issues previously often left to the councils: such as carrying out 
consumer satisfaction surveys; building into their contracts provision for ensuring that patients do not have to wait excessively long in outpatient departments; devising criteria for measuring the quality of life on the ward (as well as criteria for assessing the quality of the medical care delivered); and using the complaints system as a new way of learning about their own organisation. In all these respects the separation of the purchaser and provider functions should make it much easier for the new health authorities to innovate without being overly defensive; they may not represent the community, but neither will they represent the self interest of the organisation in the traditional way.

All this would therefore suggest that the main responsibility of community health councils will be to monitor the health authority rather than the services being provided and that their new function will be to look at whether in fact managers are taking adequate account of consumer interests in drawing up contracts and in the way they assess adequacy, accessibility, and appropriateness. No community health council can possibly represent the sheer diversity of often conflicting consumer interests in any population: given resource constraints, satisfying one group of consumers may mean leaving another lot frustrated. Surely the crucial responsibility of community health councils is, therefore, to audit the management and to give voice if managers interpret the consumer interest in an excessively technocratic or paternalistic way. But this argument needs to be qualified in one respect. The membership of the councils is deliberately biased towards the representation of the most vulnerable and least articulate consumers of NHS services, such as the elderly, the mentally ill, and the handicapped ${ }^{8}$ - those with the least ability to assert their own interests. With regard to these groups there may well be a strong case for members of community health councils to continue to monitor the quality of the services rather than to concentrate on monitoring the quality of management. Successive reports from the Health Advisory Service have made it clear that there is still cause for anxiety and that close contacts may be necessary to show what - is happening. ${ }^{9}$

In summary, then, the new managerialism of the NHS will also call for a new consumerism, including a more prominent, if rather different, role for community health councils. Though in the past much irritation was caused by community health councils interpreting their function as one of challenging NHS providers, their main function may well be to challenge NHS managers. This responsibility will require more $\frac{\bar{\sigma}}{\bar{n}}$ specialist skills as the NHS management process itself $\frac{\sigma}{\sigma}$ becomes more professional, and that may mean that the $\stackrel{\Phi}{\circ}$ councils will need access to skills to match those of the is accountants, planners, and public health specialists in the $\overrightarrow{0}$ new managerial system.

Professor of Social Policy,

Centre for the Analysis of Social Policy,

University of Bath,

Bath BA2 7AY

Secretary of State for Social Services. National Health Service reorganisation: England. London: HMSO, 1972. (Cmnd 5055 .)

2 Department of Health and Social Security. Care in action. London: HMSO, 1981. 3 Secretaries of State for Health, Wales, Northern Ireland and Scotland. Working for patients. London:
HMSO, 1989. (Cmnd 555.)

4 Jobling R. Reins tighten up for future CHCs. Health Service fournal 1990 Feb 22;278.

5 Standing Committee E: National Health Service and Community Care Bill. Third sitring. House of Commons Official Report (Hansard). 1990 January $9 \cdot 164: \mathrm{col} 76$.

Commons Official Report (Hansard). 1990 andary 9,164 .col 76 . Am C. Managing health services:

Advanced Urban Studies, 1986.
Day P, Klein R. The politics of modernization: Britain's National Health Service in the 1980s. The Milbank Quarterly 1989;67:1-35. Klein R, Lewis J. The politics of consumer representation. London: Centre for Studies in Soctal Policy,
1976.

9 Day P, Klein R, Tipping G. Inspecting for quality. Bath: Centre for the Analysis of Sccial Policy

\section{Graves' ophthalmopathy}

\section{Close liaison between physician and ophthalmologist essential}

Most patients with Graves' disease have clinically apparent eye signs when first seen, though these may precede the onset of hyperthyroidism or follow its successful treatment by many years. Like the hyperthyroidism the ophthalmopathy is immunologically mediated, and the extraocular muscles seem to be the main target. Even in patients without clinical evidence of ophthalmopathy damage to the eye muscles may be show by computed tomography' or ultrasonography. ${ }^{2}$ The extraocular muscles undergo lymphocytic infiltration and are swollen, often to many times their normal size, by oedema. This is due to the hydrophilic properties of glycosaminoglycans, which are released by proliferating fibroblasts. ${ }^{3}$ As there is little space in the orbit the increased muscle mass causes a rise in retrobulbar pressure, which may lead to exophthalmos, excessive lacrimation, exposure keratitis, corneal ulceration, and-more seriously-a compressive optic neuropathy with reduction in vision. ${ }^{4}$ Paradoxically, the greatest visual loss may occur in patients with minimal exophthalmos. The function of extraocular muscles is impaired, and diplopia is common.

The mechanism underlying the retrobulbar immune damage is not known: no antibody has been identified that is in any way similar to the thyroid stimulating hormone receptor antibody responsible for the hyperthyroidism. Nor is it known whether the ophthalmopathy and hyperthyroidism of Graves' disease are two closely related but independent organ specific autoimmune disorders (such as primary atrophic hypothyroidism and pernicious anaemia) and, if so, what the antigenically unique retrobulbar tissue is or whether they have a common immunopathogenesis and, if so, what the $\mathcal{O}$ shared antigenic determinant is.

Does treatment of the hyperthyroidism of Graves' disease influence the progress of the ophthalmopathy? Published 0 reports are bedevilled by claims and counterclaims. ${ }^{56}$ Most $\underset{\omega}{N}$ patients with Graves' disease are treated with iodine-131, and 2 there is anecdotal evidence that ophthalmopathy may worsen $\stackrel{0}{\subset}$ after this treatment, presumably in association with the release of thyroid antigen. It has been suggested, indeed, that $\stackrel{+}{+}$ the administration of radioactive iodine is an inappropriate $\vec{\circ}$ treatment in patients with considerable eye lesions. ${ }^{5}$ Never- $\stackrel{\mathbb{D}}{\circ}$ theless, a recent report by Bartalena et al is reassuring: this $\stackrel{\mathbb{Q}}{\mathscr{Q}}$ showed that prednisolone started at the same time as the administration of ${ }^{131} \mathrm{I}$ in a dose of roughly $30 \mathrm{mg}$ daily for one month and gradually withdrawn over the next three months prevented either the onset of or deterioration in mild ophthalmopathy. ${ }^{7}$ For patients with moderate or severe eye $\stackrel{\rightleftharpoons}{\rightleftharpoons}$ disease the sensible treatment seems to be the administration of a high dose of carbimazole ( $40 \mathrm{mg}$ daily) combined with thyroxine $150-200 \mu \mathrm{g}$ daily. This regimen is based on two principles: firstly, the hope that the well established immuno- 